\title{
Problems of Socialization of the Personality in the Conditions of Digitalization of Economy
}

\author{
M.V. Kivarina, Doctor in \\ Economics, Assoc. Prof., \\ A.N. Makarevich, PhD. in \\ Economics, Assoc. Prof., \\ Yaroslav-the-Wise Novgorod \\ State University
}

\author{
173003, Veliky Novgorod, \\ st. Bolshaya Sankt- \\ Peterburgskaya, 41, tel. \\ 88162627244, e-mail: \\ novsu@novsu.ru
}

\begin{abstract}
The problem of socialization of the individual, the specifics of professional development, the issues of training personnel are constantly in the focus of attention of many researchers. They become especially relevant in the era of the digital economy. The article reveals the essence of the processes of socialization of the individual under the influence of information technology. Several types of socialization (virtual, informational, etc.), the influence of the information and communication environment on the formation and socialization of the individual are considered. Negative processes are also noted, when computerization leads to persistent dependent behavior. All this determines the importance and severity of the complex interdisciplinary problem of socialization of the individual in the conditions of information processes.
\end{abstract}

Scientific understanding of the problem of the formation of personality passes several stages from the perception of the individual as a passive subject of the process of socialization to the selection of him as an active actor in his own internal development of the individual and the society. The purpose of the article is to identify problems of socialization of the individual in the conditions of digitalization of the economy based on a comparative analysis of traditional socio-paradigms and to identify the main ways to solve them.

Keywords - socialization of the personality, digital economy, information technologies, "communicative blocking", personal helplessness, personal maturity.

\section{INTRODUCTION}

Today, Russian society faces new threats and challenges that demand high demands on people's intellectual and adaptive abilities, as well as institutions that promote socialization of the individual. One of the main threats - the preservation of backwardness in Russian society - is largely due to the low information culture and ineffective processes of socialization of the individual.

This problem is very relevant in Russia, where there is a high uneven integration of social layers in the information space; numerous social groups of Russians today do not have the opportunity and motivation to form an information culture. The lack of interest in the knowledge and capabilities of information and communication technologies (or restricting this interest only in recreational opportunities) reduces the intellectual and creative abilities of a person and, therefore, his economic and social activity, limits mobility, educational opportunities and many other services. In the conditions of increasing information surplus and mobility of all social structures, such groups cannot form adequate, successful models of behavior and are becoming increasingly socially unprotected.

Thus, there is a contradiction between the needs of Russian society to integrate into the global information space and the lack of informationally educated citizens, which generates digital poverty and creates socialization problems. The purpose of the article is to identify the problems of socialization of the individual in the conditions of digitalization of the economy and to identify the main ways to solve them.

To achieve this goal, the following problems are solved in the article: 1) the concept and essence of the socialization of the individual under present conditions is explored; 2) analyzing the mechanisms of education and socialization of the individual; 3) identify the problems of socialization of the individual in the digital economy and propose ways to overcome them.

The study is based on a historical approach using the methods of logical-structural, situational and comparative analysis. The findings and recommendations can become the basis for transforming the process of socialization of the individual in the current digitalization of the economy.

\section{LITERATURE REVIEW}

Global information processes leave their imprint on all social phenomena and events, including, and the processes of socialization. These changes concern all aspects of socialization: institutions, agents, channels, mechanisms and personality. The scale of such a transformation in the conditions of the information space forces some authors to talk about virtual socialization [1], information [2,3], media socialization $[4,5]$, cybersocialization [6], Internet socialization [7].

Virtual socialization is considered as process of occurrence of the Internet user on sociocultural environment of local communities by means of development of technologies of communication, information culture, social navigation, information literacy and social norms, values and 
role requirements [8]. The virtual socialization and virtualization considered most often in the negative plan are closely connected. Virtualization is the process of substituting real space for virtual space There is the new type of alienation, characterized by the person from own body during use of computer technologies. Virtual socialization is considered uncontrolled and potentially dangerous spontaneous socialization of younger generation, owing to age incapable independently to estimate risks and restrictions in use of Internet resources. Virtual socialization, according to some researchers, should be considered as the sharpest on sociocultural and medico-physiological resonance complex crossdisciplinary problem of the changing theory of education.

Infosocialization is the result of learning, as well as the readiness to reproduce and analyze by the individual the actual component of the information experience of modern society, including the skills of working with information and information and communication technologies. Infosocialization in its content is a process of informational formation of the personality, carried out in two spheres: information activities and information communications [9]. The process of infosocialization proceeds in stages and includes information adaptation (adaptation to the information space, requirements and laws of the functioning of information flows), infotainment (inclusiveness and independent interactions of the individual in the information space, conscious choice of the types and forms of information activity by the individual) and infactivity (the ability of the individual to make changes in the information space, when this is necessary and expedient).

Media socialization (socialization under the influence of the media) consists in the acquisition by the individual of social experience mainly based on artificial media representations, in the absence of participation in this process of a socializing environment [10]. Mechanisms of media socialization are mechanisms of copying and suggestion.

The concept of cybersocialization in scientific circulation was introduced by V.A. Pleshakov in 2005. Cybersocialization (socialization of the individual in cyberspace) is viewed as a process of qualitative changes in the structure of the self-consciousness of the individual and the needs-motivational sphere of the individual, which occurs under the influence and because of human use of modern information, communication, computer and digital technologies in the context of mastering and reproducing culture within the framework of personal life activity [11]. Various authors offer different classifications of factors of cybersocialization. So, there are: megafactors (cyberspace, Internet, cellular communication); macrofactors (national domain zone, e-mail services of the Internet environment, social networks of the Internet environment, search engines, file-sharing networks, Internet advertising, the blogosphere, mass on-line games); Mesofactors (wiki projects and Internet dictionaries, Internet TV and radio, IP telephony, forums, chat rooms, online stores, online auctions, electronic payment systems, computer or console games) and microfactors (PC software and cell phones, a personal area of cyberspace, a game character in a computer game). Cybersocialization is an innovative social and pedagogical phenomenon and the most important modern kind of socialization.

The term "Internet socialization" was introduced by A.I. Luchinkina in 2011 with the aim of considering virtual space as a separate source carrying the functions of the institution of socialization of the modern personality. Internet socialization is the process of expanding the user's social experience when entering the social and cultural environment of the Internet, which occurs through the assimilation of information technologies and information culture. During Internet socialization, personal activity as an internal subjective factor of socialization, manifested in relation to action or action through the mechanisms of self-expression, inclusion, social facilitation and conformity, acquires special significance. The mechanism of self-expression is expressed in increasing the opportunities for self-expression in one's deed, deed, attitude, creation of new virtual personalities, election of new behavior strategies, new ways of selfpresentation. Inclusion is expressed in the user's own choice of a group or topic, the volume and quality of information about himself, the degree of involvement in social relations on the Internet. Social facilitation provides the stimulation of activities in the network, facilitating interaction in the network and increasing the efficiency of activities. Conformity ensures the acceptance of the norms of the informal group and an agreement with its rules. These mechanisms of Internet socialization underlie the construction of a virtual personality by the user and its social space [12].

As can be seen from the above definitions, all researchers reduce the essence of the concepts they introduced to changes in the spheres of communication, activity and selfawareness of the individual under the influence and because of the use of modern information, communication, computer and digital technologies, the Internet and social networks. These changes relate to many aspects of socialization, but the essence of socialization does not change.

At the center of the author's approach to the study of socialization of the individual is the effect of "communicative blocking." The progress of information and communication technologies leads to a situation in which the knowledge and experience of older generations cannot be effectively used by young people, because they are losing their significance due to rapidly developing social transformation processes, and the process of socialization of young people in these conditions looks very complex and contradictory.

\section{METHODS OF RESEARCH}

Throughout all history of scientific research of process of socialization, it is possible to allocate two main approaches defining an opposite role of the individual in the system of social interactions. Supporters of the first (subject and object) approach define the person as passive object of influence of society, and socialization is process of adaptation of the individual to "culture" of this society. This approach more captures the essence of process of formation, education of the personality, but not socialization when social institutes 
unidirectional influence the person, impose on it the certain matrix consisting of a set of socially expected social roles, the cultivated behavior models, traditional values of society [13].

The second approach (subject and subject) most objectively determines the content of process of socialization. Assigning to the person a part of the active subject during socialization when it not only acquires and adapts to traditional norms, values, customs, behavior models, but also models, transforms, gives innovative orientation to development as inner world, so the social environment. Then he can be capable to change and create new norms and forms of interaction of the individual with the social environment [14].

Authors of article adhere to the second approach, considering socialization as bilateral process, the role of each separately taken individual allowing to realize the importance. Besides, if was considered earlier that the personality is socialized only at children's and youthful age, then today socialization is the continuous process covering only all age groups.

\section{RESULTS AND DISCUSSION}

Processes that take place in all spheres of social life affect the personality, its living space, its internal state. Modern man is constantly under the influence of many factors: both man-made and those of social origin, which cause a deterioration in his health. The physical health of a person is inextricably linked with the psychic. The latter, in turn, is related to the person's need for self-realization, i.e. provides the sphere of life that we call social. A person realizes himself in society only if he has a sufficient level of psychic energy, which determines his capacity for work, and at the same time sufficient plasticity, harmony of the psyche, which allows him to adapt to society, to be adequate to his requirements. Mental health is a necessary condition for the successful socialization of the individual.

Statistics show that people free from any kind of mental disorder currently only average $35 \%$. The stratum of people with pre-painful conditions in the population reaches considerable sizes: according to various data, from 22 to $89 \%$. However, half of the carriers of mental symptoms independently adapt to the environment.

The success of socialization is assessed by three main indicators:

a) a person reacts to another person as an equal;

b) a person recognizes the existence of norms in relations between people;

c) a person recognizes the necessary measure of loneliness and relative dependence on other people, that is, there is a certain harmony between the "lonely" and "dependent" parameters.

Criterion of successful socialization is a person's ability to live in the conditions of modern social norms, in the system "I am a society". However, it is increasingly rare to meet people who meet these requirements. Increasingly, we are confronted with manifestations of hampered socialization, especially among the younger generation. As the results of recent studies show, children with disabilities in behavior, deviations in personal development do not become less, despite the existence of an extensive network of psychological services.

So, the problem of aggression in the teenage environment preserves its practical significance. Undoubtedly, aggressiveness is inherent in any person. The lack of it leads to passivity, statements, conformity. However, its excessive development begins to determine the whole face of the personality: it can become conflict, incapable of conscious cooperation, and thus complicates the comfortable existence of the person among the surrounding people. Another problem that causes public anxiety is the violation of social norms and rules by adolescents, reluctance to obey them. This is a manifestation of a violation of the process of socialization. More and more children appear in the group of deviant adolescents. Also, the problem of modern society is the increase in cases of suicide among the children's population. The scale of the problem is much wider than it seems at first glance. After all, statistics usually include realized attempts to leave life, but even more people with a tendency to suicidal behavior remain unaccounted for [15].

All this allows us to conclude that in modern conditions the socialization of the individual is difficult. Especially this is vividly demonstrated by representatives of the younger generation, who have a low ability to adapt, which makes it difficult for them to absorb the social space in an adequate way. As a rule, unresolved difficulties of the same age entail the emergence of others, which leads to the formation of a whole symptomatic complex, fixed in personal characteristics. Speaking about the importance of forming a socially active personality of the younger generation, we, nevertheless, in fact are faced with the difficulties of their adaptation to changing conditions.

Here lie the origins of such a social problem as the experience of loneliness among young people. If several decades ago the problem of loneliness was considered a problem of the elderly person, today its age threshold has sharply decreased. A certain percentage of single people are observed among students. Let's note, that at lonely people social contacts are minimal, their personal communications with other people, as a rule, either are limited, or absent.

As the extreme poles of socialization, we see the personal helplessness and personal maturity of the subject. Undoubtedly, the goal of society should be the formation of a mature personality with such qualities as independence, responsibility, activity, independence. These characteristics are inherent most often to an adult person, but their foundation is laid already in childhood. Therefore, all efforts of teachers, society should be aimed at the formation of the indicated qualities. Personal helplessness develops in the process of ontogeny under the influence of several factors, including the system of relationships with others. Finding a person at one or another point of the continuum "personal helplessness personal maturity" is an indicator of his socialization, and in general subjectivity. 
Socialization of personality is a continuous and multifaceted process that continues throughout the life of a person. However, most intensively it occurs in childhood and adolescence, when all basic value orientations are laid, basic social norms and deviations are assimilated, and the motivation for social behavior is formed. The process of human socialization, its formation and development, becoming as a person occurs in interaction with the environment, which has a decisive influence on this process through a variety of social factors.

Society is important for the socialization of the individual. This person is gradually mastering this nearest social milieu. If at birth the child develops mainly in the family, in the future he learns more and more new environments - preschool, school, friends' companies, discotheques, etc. With age, the child's "territory" of the social environment is expanding more and more. Thus, the person as though constantly searches and finds that environment which for it in the greatest degree is comfortable, where it is understood better, concern to it with respect, etc. For the process of socialization, it is important what kind of attitudes an environment forms in which a person is located, what social experience can accumulate in him in this environment positive or negative. Adolescence, especially from the age of 13-15 is the age of the formation of moral beliefs, the principles by which a teenager begins to be guided in his behavior. At this age, there is an interest in worldview issues, such as the emergence of life on Earth, the origin of man, the meaning of life. Formation of the adolescent's correct attitude to reality, persistent beliefs must be given paramount importance, since it is at this age that the foundations of conscious, principled behavior in society are laid, which make themselves felt in the future [16].

Moral beliefs of the person are formed under the influence of the surrounding reality. They can be wrong, wrong, distorted. This is the case when they are formed under the influence of random circumstances, the bad influence of the street, unseemly acts. In close connection with the formation of moral convictions of young people, their moral ideals are formed. This they are significantly different from younger schoolchildren. As studies have shown, ideals in adolescents manifest themselves in two main forms. The teenager as an ideal is the image of a person, in which he sees the embodiment of highly valued qualities. With age, the young man has a noticeable "movement" from the images of close people to the images of individuals with whom he does not directly communicate. Senior teens begin to make higher demands on their ideal. In this regard, they begin to realize that others, even those who are very beloved and respected by them, are for the most part the most ordinary people, good and worthy of respect, but are not the ideal embodiment of the human person. Therefore, at 13-14 years of age, the search for an ideal outside of close family relationships takes on special development.

In the development of youth's knowledge of the surrounding reality, a moment comes when the object of cognition is a person, his inner world. It is in adolescence that there is an orientation toward cognition and assessment of the moral and psychological qualities of others. Along with the growth of such interest in other people, adolescents begin to develop and develop self-awareness, the need for comprehension and evaluation of their personal qualities.

The formation of self-consciousness is one of the most important moments in the development of the personality of the adolescent. The fact of formation and growth of selfconsciousness leaves an imprint on the entire mental life of the adolescent, on the nature of his educational and work activities, on the formation of his attitude to reality. The need for self-consciousness arises from the needs of life and activity. Under the influence of growing demands on the part of others, the adolescent needs to assess his own abilities, to realize what personality features help them, on the contrary, prevent them from meeting the requirements. The key role in the development of the young man's self-awareness is played by the judgments of others. The aspiration to self-education the desire to consciously influence oneself, to form such qualities of the person, which he considers as positive, and to overcome negative features, to struggle with his shortcomings, appears and acquires a rather noticeable significance in the adolescent.

In adolescence, character traits begin to take shape and become established. One of the most characteristic features of a teenager, associated with the growth of his self-awareness, is the desire to show his "adulthood." The young man defends his views and judgments, ensuring that adults are considered with his opinion. He considers himself old enough, wants to have the same rights with them. Overestimating the possibility of their age abilities, teenagers come to the belief that they are no different from adults. Hence their desire for independence and a certain "independence", hence - painful self-esteem and resentment, an acute reaction to the attempts of adults who underestimate their rights and interests. It should be noted characteristic of adolescence, increased excitability, some dissatisfaction with the nature, relatively frequent, rapid and sudden changes in mood [17].

Young people who have lost their landmark, who do not have support among adults, are trying to find an ideal or a model to follow. Thus, they are adjacent to one or another informal organization. The peculiarity of informal associations is the voluntary entry into them and a steady interest in a specific goal, idea. The second feature of these groups is rivalry, based on the need for self-assertion. A young man strives to do something better than others, to get ahead of something even the people closest to him. This leads to the fact that within the youth groups are heterogeneous, they consist of many micro-groups, united based on sympathies and antipathies. Many of the non-formals - people are very extraordinary, talented. They spend days and nights on the streets without knowing why. No one organizes these young people, does not force them to come here. They flock themselves - all very different, and at the same time something subtle similar. Many of them, young and full of strength, often want to howl at night from longing and loneliness. Many of them are devoid of faith, whatever it is 
and therefore are tormented by their own unnecessariness. And, trying to understand themselves, they go in search of the meaning of life and adventures in informal youth associations. It is generally accepted that the main thing for adolescents in informal groups is the opportunity to relax and spend their free time. From the sociological point of view, this is wrong: the rest is on one of the last places in the list of what attracts young people to informal associations - only slightly more than $7 \%$ of young people talk about it. About $50 \%$ find the opportunity in an informal environment to communicate with people close to them in spirit. For $11 \%$, the most important thing is the conditions for the development of their abilities, which arise in informal groupings.

Changing the forms and ways of presenting information, its sources and content, the volume and speed of receipt, the technology of obtaining and working with information, the principles of information interaction bring to the forefront the relationships of individuals based on virtual nature [18]. The nature of the relationship, especially the intergenerational, is changing in these conditions.

The process of socialization of the individual today is largely realized in the virtual reality created by the Internet and virtual technologies. Such significant changes require the need to change the entire education system as an essential element of the socialization of the individual. Pedagogical activities for the implementation of the socialization of students should be aimed at the introduction of social and pedagogical technologies for the positive use of the Internet, information and communication technologies and social networks.

New mechanisms of socialization and personal education associated with modern information and communication technologies require the use in the educational process of more modern, technological, attractive forms of educational interaction for adolescents, among which network forms are the most effective and economical. At the same time, it should be borne in mind that the invasion of human virtual forms of communication does not negate the necessity and regularities of "living" communication between people. Moreover, new forms of mediated communication are based on the experience of direct human communication, and all socio-psychological reactions and the social and pedagogical effects resulting from them are extrapolated to all processes taking place in information socialization.

The Internet occupies a key position in the modern information and communication space, ensuring human access to media and information resources of several types. The virtual world pushes back to the background classical institutions of socialization - family, school, real friends and peers [19]. But the Internet should not replace and replace the role of classical institutions (families, schools, etc.) in the socialization of youth and that it is necessary to take into account (and use) the unique social and pedagogical potential of the socializing Internet environment - its accessibility, mobility and efficiency, relative security and anonymity, freedom of expression, capable of actively influencing both positive and negative potencies in the process of socialization of older students on the Internet.

At the same time, one should remember about the negative impact of the Internet and computer technologies. Social networks, as a progress for society, have become a regress for interpersonal communication between people. According to scientists, the computerization of modern society in some cases leads to persistent dependent behavior.

Socialization of personality occurs through the functioning of a certain mechanism:

1) The traditional mechanism of socialization is the adoption by man of norms, standards of behavior, views, stereotypes that are characteristic of his family and immediate environment. This assimilation occurs, as a rule, on an unconscious level with the help of imprinting, uncritical perception of the prevailing stereotypes. The effectiveness of the traditional mechanism appears very clearly when the person knows "how to", "when necessary", but this knowledge contradicts the traditions of his environment.

2) The institutional mechanism of socialization, as it follows from the name itself, functions in the process of human interaction with the institutions of society and various organizations, both specially created for its socialization, and implementing socializing functions along the way, in parallel with its basic functions (production, public, club and other structures, as well as mass media).In the process of human interaction with various institutions and organizations, there is an increasing accumulation of relevant knowledge and experience of socially acceptable behavior, as well as experience in imitating socially approved behavior and conflict and conflict-free implementation of social norms. It must be borne in mind that the mass communication media as a social institution affect the socialization of a person not only through the transmission of certain information, but also through the presentation of patterns of behavior of the characters of books, movies, television programs.

3) The stylized mechanism of socialization operates within a certain subculture. A subculture is a complex of moral and psychological traits and behavioral manifestations that are typical for people of a certain age or a certain professional or cultural stratum, which creates a certain style of behavior and thinking for one or another age, professional or social group.

4) The interpersonal mechanism of socialization functions in the process of interaction of a person with subjectively significant persons for him. Significant for him may be parents (at any age), any respected adult, a peer friend of his or her opposite sex. But it is not uncommon for a person to communicate with important people in groups or organizations can exert an influence on a person that is not identical to that of the group or organization itself.

The socialization of person, and especially of children, adolescents, young men, occurs through all these mechanisms. However, in different age, sex and socio-cultural groups, in specific people the relationship between the role of socialization mechanisms is different, and sometimes this difference is very significant. 
The changes that have occurred in the last 10 years in all spheres of the political, economic and social life of Russian society have given rise to numerous problems. One of the most urgent is the critical interpretation of changes in social and spiritual life, the determination of trends in further development, the choice of the structure and content of social education as a controlled institution for the socialization of children.

Modern society requires from man not only polytechnics of knowledge, high cultural level, deep specialization in certain areas of science and technology, strong knowledge, skills and skills in training activities, but also the ability to live, coexist in society. The main parameters of the child's personal development for today can be considered his orientation to universal human values, humanism, intelligence, creativity, activity, self-esteem, independence in judgments. It is from these skills and qualities that the success of man and society depends largely on overcoming the contradictory conditions of social life.

The problems of socialization in modern Russian society are related to three factors:

1) the change (destruction) of the value system, because of which the older generation cannot always prepare young people for life in the new conditions;

2) radical and very rapid change in the social structure of society; the inability of many new social groups to ensure the reproduction of their ranks;

3) weakening the system of formal and informal social control, as a factor of socialization.

One of the most obvious features of modern socialization is its duration in comparison with previous periods.

In modern society, a paradoxical situation is created on the one hand, our society is increasingly confronted with tasks (both professional and everyday), the successful solution of which is beyond the power of a single person and requires the cooperation of groups of people. Such cooperation implies the knowledge, skills and skills of interpersonal interaction. As a result, specialists in the modern domestic labor market are becoming more and more in demand, the basis of their activities is precisely interaction with other people psychologists, lawyers, managers. On the other hand, the achievements of science and technology are aimed at making a person as independent and independent as possible in all spheres of life, and sometimes even isolating him from society (for example, the proliferation of personal computers, personal stereoscopic players, home theaters, etc.). Situations that used to involve close communication with other people lose their relevance; more and more people choose the profession of the kind of "man-machine" or "man-sign system".

This trend in society negatively affects the process of socialization of modern man. The assimilation of social experience does not end with the completion of the stage of purposeful inculcation of generally accepted rules of norms in schools and other educational institutions, this process spontaneously continues throughout life. Since the process of socialization is inextricably linked with the individualization of the individual, its formation and development, it can be said that modern society to some extent hinders the development and, moreover, the self-development of the individual.

In modern conditions, because of the complexity of professional orientation, which often leads to the wrong choice of the profession or the wrong selection of the profession, we get not only an inferior specialist, but also a dissatisfied person who finds it difficult to find a place in life [20].

Socialization as a social phenomenon is determined by the nature of society itself, its properties and needs. In the conditions of gradual transition from one sociocultural reality to another, the criteria and norms of human vital activity change, as well as the conditions for creative self-realization. In connection with this, the study of the whole complex of changes that characterizes the process of socialization of a person, the identification of specific factors, conditions and social contradictions that determine the formation of a new type of personality - a participant in social transformations becomes especially urgent.

Another urgent and most important problem for us today is the influence of market values on the socialization of the individual. Our society is going through a crucial historical stage - the emergence of market relations. It relates to the change not only of economic relations, but also of the entire system of social relations, which is based on them. The entire way of life of people changes, and this, of course, cannot lead to a change in value orientation, motivation of behavior and the entire process of socialization of the individual.

The essence of market relations is economic liberalism, competition, the pursuit of profit. They affect the value orientations of the individual ambiguously. On the one hand, they undoubtedly awaken initiative, activity, energy of people, expand opportunities for the development of abilities and creativity of the individual. But we must not forget or ignore the second side of the influence of market values on the formation of the individual. It is that the development of economic liberalism and competition for profit, as K. Horney, E. Fromm, J. Homans, R. Merton and others have shown well, leads to such consequences as double morality, general alienation, mental frustrations, neuroses, etc. The values of the personality are, as it were, passed through the prism of the market and acquire the character of market values [21]. Not only the material, but also the spiritual life of society and personality are built according to the laws of market relations and economic exchange. In the conditions of domination of market relations, a person often loses his higher values, which make up the meaning of her life. And this leads to the formation of an existential vacuum.

In themselves, market relations and the goals and values associated with them cannot have a self-sufficient meaning, i.e. act as the highest values. It is always only values-a means for the person's own development. The market values that pursue the goals of material enrichment are, of course, necessary. But behind them there are always (and should not be forgotten) more fundamental values of the spiritual development of the individual. A key role in their 
assertion in life belongs to philosophy. Although the market has an internal logic of its development, state structures should not be excluded from regulation of market relations. The economy should be socially oriented. The values of economic liberalism and social justice must be integrated in a single synthesis. Only with this condition can we socially protect the poor and give freedom of action to a socially active and capable part of the population [22].

One cannot help but touch upon this aspect of the problem, as irrational and pseudoscientific values are spreading in our society. An avalanche of information systematically falls on the person today, the content of which is associated with pseudoscience (mysticism, occultism, astrology, magic, witchcraft, etc.). Under these conditions, non-critical thinking and perception of reality are formed involuntarily, unconsciously. Rationalism is replaced by irrationalism; any functional myth is considered rational. A type of consciousness is formed in which real contradictions are not considered, the principle of objectivity is replaced by subjectivism, the logic of reason is replaced by faith and suggestion. In general, the processes of socialization are aimed at combining the interests of the individual and the organization, whatever they are.

It should be noted separately and pay special attention to the most vital component of socialization - the formation of a world view. The transformation of society and the image of the World, as well as the types of personality it produces, their relations to social reality, to nature, to each other, generates needs for new ideological orientations that would provide better forms of social life. In the era of the scientific and technological revolution, two tendencies are manifested here: on the one hand, the formation of a worldview is facilitated, and, on the other, difficult. A worldview is the unity of two moments. One moment is knowledge, information about reality, and the other moment is the position, attitude to the environment, humanity, to this society, to oneself. Today, information is given easily, and positioning is a complicated process.

For effective socialization of the individual, it is necessary to carry out the following activities: introduce programs of social and psychological orientation of workers; to implement vocational training programs in the closest possible unity with orientation programs; to carry out a performance evaluation, with a view to maximizing and extending feedback to the employee; identify and offer work that involves the challenge, in order to stimulate the initiative and more fully reveal the creative potential of workers; appoint "chiefs" and mentors in order to strengthen informal influence on workers in the right direction.

The problem of the socialization of the individual (and not only the emerging personality, that is, the young man) is very acute, and because, in connection with a sharp drop in the birth rate in most European countries, and in Russia, the phenomenon called "population aging" takes place. Adults and elderly people are each year more and more quantitatively part of the population of many countries. This significantly increases the importance of the problem of socialization of adults, forces politicians, philosophers and scientists investigating the individual and society to take a fresh look at the place and role of the elderly in society, and calls for new research, both on theoretical and practical levels.

The process of socialization of the individual now takes place under the influence of several factors: technologization, globalization, information processes, convergence of communicative spaces have significantly affected the content of all aspects of human life.

To solve the problems of socialization of the population, everyone should understand that gadgets cannot replace "live" communication. We need to spend more time in the circle of relatives and friends, to communicate, to share, not to be withdrawn. It is also useful to read books and know what is happening in the region, in the country and in the world. After all, this is self-development.

In turn, the state should take measures to address the problems associated with the choice of professions. As the study showed, most believe that pay is the main factor. And this means that many works for unloved work. This leads to a deterioration in the state (both moral and physical) of the employee, and thus to a deterioration in labor productivity and a decrease in the efficiency of all production and economic activities.

Thus, successful socialization of a person in conditions of digitalization is not only a matter of sociology, but also of the economy, since it is a predetermining factor in increasing the efficiency of the entire system of management.

\section{CONCLUSION}

Proceeding from the foregoing, we can conclude that one of the most important universal aspects of generations is socialization. The term "socialization" denotes the totality of all social processes through which the individual assimilates and reproduces a certain system of knowledge, norms and values that enable him to function as a full member of society.

So, socialization is the process by which an individual becomes a member of society, assimilating its norms and values, mastering these or those social roles. At the same time, the older generation passes on their knowledge to younger people, forms their skills necessary for independent life. So, one generation replaces another, providing continuity of culture, including language, values, norms, customs, morals. It is through systematic interaction with other people that the individual develops his own beliefs, moral standards, habits all that creates the uniqueness of the individual. Thus, socialization has two functions: the transfer of culture from one generation to another and the development of the "I". Socialization includes not only conscious, controlled, purposeful influences, but also spontaneous, spontaneous processes that somehow influence the formation of personality.

Thus, the reform of Russian society led to a change in the standards of successful socialization of the individual, the totality of rules for the transfer of social norms and cultural values from generation to generation. 


\section{REFERENCES}

[1] Rotaru, I. Virtual Communities, a Challenge for Today's Concepts of Identity and Citizenship // Procedia - Social and Behavioral Sciences, Vol. 159, 23 December 2014, pp. 37-41. doi: 10.1016/j.sbspro.2014.12.324.

[2] Baygin, M., Yetis, H., Karakose, M., and Akin, E. An effect analysis of industry 4.0 to higher education // 15th International Conference on Information Technology Based Higher Education and Training (ITHET), pp. 1-4, 2016. doi: 10.1109/ITHET.2016.7760744.

[3] Ifinedo, P. Information systems security policy compliance: An empirical study of the effects of socialisation, influence, and cognition // Information \& Management, vol. 51, Issue 1, January 2014, pp. 69-79. doi: 10.1016/j. im.2013.10.001

[4] Kammerl, R., and Kramer, M. The changing media environment and its impact on socialization processes in families // Studies in Communication Sciences, vol. 16, Issue 1, 2016, pp. 21-27. doi: 10.1016/j.scoms.2016.04. 004.

[5] Leidner, D.E., Gonzalez, E., and Koch, H. An affordance perspective of enterprise social media and organizational socialization // The Journal of Strategic Information Systems, Available online 4 April 2018, In Press. doi: 10.1016/j.jsis.2018.03.003.

[6] Jiang, P., Ding, K., and Leng, J. Towards a cyber-physical-socialconnected and service-oriented manufacturing paradigm: Social Manufacturing // Manufacturing Letters, vol. 7, January 2016, pp. 15-21. doi: 10.1016/j.mfglet. 2015.12.002.

[7] Honnekeri, B.S., Goel, A., Umate, M., Shah, N., and De Sousa, A. Social anxiety and Internet socialization in Indian undergraduate students: An exploratory study // Asian Journal of Psychiatry, vol. 27, June 2017, pp. 115-120. doi: 10.1016/j.ajp.2017.02.021.

[8] Ahuja, M.K., and Galvin, J.E. Socialization in Virtual Groups // Journal of Management, vol. 29, Issue 2, April 2003, pp. 161-185. doi: 10.1016/S0149-2063(02)00213-1.

[9] Avdeeva, A.V. Influence of information and communication technologies on the process of socialization // Bulletin of Tambov State Technical University, vol. 18, Issue 3, 2012, pp. 771-776.

[10] Luchinkina, A.I. Features of socialization of Internet users // Scientific notes of the Crimean Engineering and Pedagogical University, vol. 2, Issue 4, 2016, pp. 137-140.

[11] Pleshakov, V.A. The theory of human cyber socialization // Moscow: Homo Cyberus, 2011.
[12] Castellacci, F., and Tveito, V. Internet use and well-being: A survey and a theoretical framework // Research Policy, vol. 47, Issue 1, February 2018, pp. 308-325. doi: 10.1016/j.respol.2017.11.007.

[13] Ashforth, B.E., Sluss, D.M., and Saks, A.M. Socialization tactics, proactive behaviour, and newcomer learning: Integrating socialization models // Journal of Vocational Behavior, vol. 70, Issue 3, 2007, pp. 447-462. doi: 10.1016/j.jvb.2007.02.001.

[14] Mainzer, K. Interdisciplinarity and innovation dynamics. On convergence of research, technology, economy, and society // Poiesis and Praxis, vol. 7, Issue 4, 2011, pp. 275-289. doi: 10.1007/s10202-0110088-8.

[15] Poteat, V.P., Espelage, D.L., and Green, H.D. The Socialization of Dominance: Peer Group Contextual Effects on Homophobic and Dominance Attitudes // Journal of Personality and Social Psychology, vol. 92, Issue 6, 2007, pp. 1040-1050. doi: 10.1037/00223514.92.6.1040.

[16] Francis, J.E., and Davis, T. Exploring children's socialization to three dimensions of sustainability // Young Consumers, vol. 15, Issue 2, 2014, pp. 125-137. doi: 10.1108/YC-06-2013-00373.

[17] Wang, Y., and Benner, A.D. Cultural socialization across contexts: family-peer congruence and adolescent well-being // Journal of Youth and Adolescence, vol. 45, Issue 3, 2016, pp. 594-611. doi: 10.1007/s10964-016-0426-1.

[18] Muromtsev, V.V. Features of socialization of the person in the conditions of modern virtual communications // Philosophical sciences, vol. 9, 2012, pp. 127-133.

[19] Brooks, S., and Longstreet, P. Social networking's peril: Cognitive absorption, social networking usage, and depression // Cyberpsychology: Journal of Psychosocial Research on Cyberspace, vol. 9, Issue 4, 2015, article 5. doi: 10.5817/CP2015-4-5.

[20] Tang, C., Liu, Y., Oh, H., and Weitz, B. Socialization Tactics of New Retail Employees: A Pathway to Organizational Commitment // Journal of Retailing, vol. 90, Issue 1, 2014, pp. 62-73. doi: 10.1016/j.jretai.2013.11.002.

[21] Baumol, W.J., and Strom, R. J. Entrepreneurship and Economic Growth // Strategic Entrepreneurship Journal, vol. 3-4, Issue 1, 2007, pp. 233237. doi: $10.1002 /$ sej.26.

[22] Song, Z., Chon, K., Ding, G., and Gu, C. Impact of organizational socialization tactics on newcomer job satisfaction and engagement: Core self-evaluations as moderators // International Journal of Hospitality Management, vol. 46, 2015, pp. 180-189. doi: 10.1016/j.ijhm.2015.02.006. 